\title{
EL DESARROLLO DEL TURISMO EN ALEMANIA DURANTE EL RÉGIMEN NACIONAL SOCIALISTA
}

\author{
Ernesto Piero Bazzetti De los Santos \\ Universidad Ricardo Palma \\ pbazzetti13@hotmail.com
}

\section{RESUMEN}

El desarrollo del Turismo durante el período de la Alemania nazi, está relacionado a la creación del $\mathrm{KdF}$, organización a través de la cual el pueblo alemán tenía acceso a un real disfrute del tiempo libre. Alemania se convertiría en poco tiempo en una potencia turística mundial y el régimen utilizaría este proceso en beneficio de los intereses políticos del nacionalsocialismo, preparando al pueblo alemán para la inminente guerra que se produciría.

\section{PALABRAS CLAVE}

Turismo, nacionalsocialismo, KdF, DAF, ocio, tiempo libre.

\begin{abstract}
The development of Tourism during the period of nazi Germany, is related to the creation of the KdF, organization through which the German people had access to a real enjoyment of free time. Germany would soon become a world tourist power and the regime would use this process for the benefit of the political interests of National Socialism, preparing the German people for the impending war that would take place.
\end{abstract}

\section{KEYWORDS}

Tourism, National Socialism, KdF, DAF, leisure, free time. 
Cuando se inicia el desarrollo de las asignaturas de introducción, fundamentos o teoría del Turismo, según se denomine, en cualquier institución académica especializada en la formación de profesionales en turismo, al margen de la estructura silábica de la misma; en la unidad correspondiente a la conceptualización del Turismo, siempre habrá que hacer referencia a la Escuela Berlinesa.

Es así como inicia el interés por escribir este artículo, al tratar de indagar porqué hubo una intensa actividad entre los teóricos alemanes del Turismo de la década de los años treinta del siglo pasado. Cabe mencionar que muchos teóricos del Turismo ya habían vertido sus conceptos desde inicios del siglo XX; pero definitivamente hay una concentración mayor de aportes en el período indicado líneas arriba. Gluksmann, Schwink, Morgenroth, Bormann, Roscher, Stradner, Benscheidt y Ehrensperger son los investigadores que forman el núcleo de la llamada Escuela Berlinesa.

Entonces la pregunta inicial fue ¿qué ocurrió en Alemania para que de pronto hubiera este repentino interés por el Turismo?, la respuesta tuvo que ver con el ascenso del régimen nazi al poder y la creación de un organismo que revolucionó el uso del tiempo libre en Alemania.

El Kraft durch Freude (KdF); traducido literalmente como Fuerza a través de la Alegría; fue una organización política alemana que se creó el 28 de noviembre de 1933 y perduró hasta 1945. Estuvo dedicada a la tarea de estructurar, vigilar y uniformizar el tiempo libre de la población en el período de la Alemania nazi. El KdF era parte del Deutsche Arbeitsfront (DAF), el Frente Alemán del Trabajo; sindicato unificado dependiente del estado nacionalsocialista. El KdF fue concebido como una herramienta y un medio propagandístico para exaltar las ventajas y virtudes del nacionalsocialismo en el pueblo, tenía la autoridad estatal en materia de viajes, excursiones y vacaciones organizando viajes terrestres y marítimos, era al mismo tiempo la agencia de viajes más importante de Alemania y se convertiría en la más grande del mundo en la década de los años treinta.

El KdF estuvo inspirado en una la organización de la Italia fascista, la Opera Nazionale Dopolavoro (después del trabajo), pero extendiendo también su influencia al ámbito laboral; en el lugar mismo de trabajo, el KdF amplió rápidamente su abanico de actividades y creció vertiginosamente para convertirse en poco tiempo en una de las organizaciones más grandes del Tercer Reich. La Opera Nazionale Dopolavoro nunca logró alcanzar el éxito o el alcance que sí logró el KdF. 
La organización defendía el principio de crear una Volksgemeinschaft (comunidad nacional), nacionalsocialista, así como el perfeccionamiento y refinamiento del pueblo alemán. Buscaba conseguir tal objetivo organizando programas de uso del tiempo libre muy bien estructurados.

Robert Ley, fundador del KdF, citaba en con frecuencia a Adolf Hitler cuando en un discurso dijo lo siguiente:

Deseo que a cada trabajador se le conceda un periodo de vacaciones suficiente y que todo se disponga de tal manera que estas vacaciones y el resto de su tiempo libre sirvan realmente de descanso y recuperación. Lo deseo porque quiero un pueblo con nervios de acero, pues la única manera de hacer política a lo grande es con un pueblo que mantiene la calma.

En otra oportunidad Hitler diría también que:

En el porvenir cada obrero tendrá sus vacaciones algunos días del año, de las que dispondrá libremente. Cada uno podrá una o dos veces en su vida hacer un viaje por mar.

Durante el Congreso de Núremberg de 1937 Hitler diría también:

Lo decisivo es conducir a nuestro pueblo hacia la grandeza a ser posible a través del camino de la alegría y de la belleza.

Un objetivo declarado fue la preservación de la paz laboral y evitar así la aparición de un sindicalismo hostil al régimen mediante el apaciguamiento del trabajador. Se buscaba asegurar la paz interna prometiéndoles a los trabajadores que podrían permitirse lujos a los que hasta entonces sólo tenían acceso las clases altas, practicar deportes caros o exclusivos como la equitación, navegar a vela o jugar al tenis y tener la posibilidad de viajar al extranjero, así como de acudir a balnearios de la costa báltica o del Mar del Norte a precios muy bajos.

El objetivo oficial fue la creación de un nuevo pueblo y sociedad alemanes. Según los teóricos nazis, el nuevo orden político y económico debía servir a la comunidad sociocultural del pueblo alemán. Se buscaba fortalecer el orgullo nacional y el espíritu comunitario, con medidas 
destinadas a que los trabajadores tuvieran más energía para el trabajo, aumentando el rendimiento laboral y por ende la productividad.

La prioridad de todos los programas era en principio eliminar las desigualdades sociales para crear una gran comunidad alemana en la que todos debían tener, independientemente de sus ingresos, las mismas posibilidades de recreo. Este sentimiento era alimentado por la propaganda del régimen y constituía un elemento necesario para llevar a cabo los ambiciosos objetivos de Adolf Hitler. Para los nacionalsocialistas, el ocio no era un fin en sí mismo, sino que debía estar al servicio del estado y del pueblo. Por lo tanto el KdF pretendía minimizar las diferencias entre las clases sociales ofreciendo al pueblo actividades de ocio propias de la clase media, a costos muy reducidos e inclusive gratuitos.

El KdF comprendía siete secciones, de las que la más importante era la de Vacaciones, Viajes y Excursiones. Con el KdF Hitler y el nacionalsocialismo introdujeron una nueva cultura del tiempo libre y de las vacaciones en el corazón del mundo laboral alemán. Las otras secciones eran, Oficina de belleza y dignidad del trabajo, Oficina de Aptitud Física y Deportes, Oficina de Educación Espiritual y Entrenamiento, Oficina de Cultura, Oficina de Etnicidad y Aduanas, Servicio de Protección de la juventud.

El gobierno nazi consideraba especialmente aptos y motivados para ir a la guerra a los individuos sanos, para lo cual era necesario impulsar entre el proletariado, el recreo, además de controlar el tiempo de ocio de los trabajadores, también se esperaba poder aumentar la producción de las fábricas de armamentos. Estos objetivos no se anunciaron oficialmente sino hasta poco antes del estallido de la guerra. El KdF fue finalmente, una preparación para la guerra.

Otro objetivo menos ideológico, pero no menos importante era impulsar la economía alemana estimulando el Turismo para sacarla de la depresión de los duros años veinte. También se esperaba que los alemanes, cuando viajaran al extranjero pudieran comparar su país con otros países en beneficio de Alemania. También debía mejorar la imagen de Alemania en el extranjero; mediante la edición de vistosos folletos el KdF tuvo bastante éxito en este aspecto hasta el estallido de la Segunda Guerra Mundial.

Desde 1933 el KdF recompensó a los trabajadores proporcionándoles a ellos, y a sus familias alternativas de ocio asequibles, como 
conciertos de música clásica y folklórica, obras de teatro, proyecciones cinematográficas, visitas a bibliotecas, excursiones de un día y vacaciones a balnearios o a los Alpes alemanes, además de actividades deportivas.

Se construyeron buques de gran tamaño como por ejemplo el Wilhelm Gustloff y el Robert Ley específicamente para realizar los cruceros organizados por el KdF pudiendo viajar pasajeros independientemente de su condición social sorteando la asignación de cabinas, con lo que eran desterradas las clases sociales en estos viajes.

Las instalaciones de estos buques destinados al Turismo tenían $5,000 \mathrm{~m} 2$ de superficie en las cubiertas instaladas para servir de solárium, así como para las actividades deportivas y recreativas, todos los camarotes eran exteriores, los comedores eran muy espaciosos, de manera que se podían servir las comidas simultáneamente a todos los pasajeros. Contaba también con piscinas y un café restaurante en la cubierta superior donde podían permanecer aún en caso de lluvia.

Debido a la gran organización, los gastos eran mínimos, por tan solo 12,15 o 16 marcos el trabajador podía veranear durante una semana, incluyendo todos los gastos de traslado, alojamiento, alimentación, etc. Esto significaba que el viaje no le costaba más que el sueldo que ganaba el obrero en un mes. Se estima que 14 días en Italia le costaba a un trabajador alemán solo 155 marcos. Incluso Eva Braun realizó un crucero en alguna oportunidad.

Los cruceros se realizaban a España, Portugal, Italia y Noruega, pero uno de los destinos especiales era la isla Madeira (Portugal). Cuando la gente recibía la comunicación de que podía realizar el crucero a Madeira, apenas podían contener su alegría. En los cruceros, se organizaban fiestas y juegos que facilitaban el viaje. Durante el trayecto imperaba un espíritu de amistad. Los viajeros podían permanecer en sus camarotes o realizar actividades recreativas como carreras de sacos en cubierta, además, se servía cerveza; por las noches se bailaba o se asistía a un concierto o al cine. Cuando llegaban los turistas alemanes se entregaban al Turismo y a observar el modo de vida de los lugareños. Cuando regresaban a Alemania, los trabajadores lo hacían con sus fuerzas renovadas y no era de extrañar que los agradecidos turistas expresaran la frase: 


\section{¡Salud y Victoria al Führer!}

Cuando empezó la guerra, los cruceros del KdF fueron convertidos en buques de uso militar debido a las nuevas exigencias militares.

El Wilhelm Gustloff sirvió como buque nodriza de submarinos, buque hospital y transporte de evacuación durante la operación ANÍBAL hacia el final de la contienda. El 30 de enero de 1945 fue torpedeado por el submarino soviético S-13 al mando de Aleksandr Marinesko, hundiéndose con 9343 personas a bordo convirtiéndose en el mayor desastre marítimo de la historia.

El Robert Ley participó en las mismas evacuaciones durante las cuales habían hundido al Wilhelm Gustloff en enero de 1945, pero sobrevivió y sirvió como buque de transporte en Hamburgo hasta marzo de 1945. El 9 de marzo de 1945 los bombarderos de la RAF encontraron al buque en el muelle de Hamburgo y lanzaron bombas que impactaron en sus cubiertas. En cuestión de segundos, el crucero estaba en llamas de proa a popa. Después del incendio, el buque quemado y oxidado quedó en Hamburgo hasta que fue remolcado a Inglaterra en 1947 para ser desguazado.

Otra muestra importante del funcionamiento del $\mathrm{KdF}$ fue la apertura de Albergues Juveniles en todo el Reich, lo que permitió corrientes de viajeros de una ciudad a otra recorriendo el país. También en diferentes regiones de Alemania; en especial en los lugares más hermosos, se construyeron más de 150 casas de recreo destinadas exclusivamente a las vacaciones de las mujeres en donde podían descansar gratamente, esto fue parte del programa de Madres Alemanas.

Crease o no tuvieron presente conceptos de sostenibilidad, cuando se inició la construcción toda la red de carreteras y autopistas alemanas, que fue en breve lapso de seis años; se tuvo especial cuidado en que el nuevo sistema de carreteras, no destruyera innecesariamente el paisaje alemán, los bosques y los hábitats de vida silvestre.

Las estadísticas oficiales mostraban qué en 1934, más de 2,3 millones de alemanes habían participado en algún viaje organizado por el KdF, para 1936 la cifra se había incrementado a 5 millones y en 1938 a 11 millones; más de la mitad de ellos veraneaban entre 7 y 10 días y el $50 \%$ eran obreros industriales. Las $2 / 3$ partes tenían un salario mensual de solo 
150 marcos. El fin perseguido por esta sección era mandar anualmente a unos 14 millones de trabajadores y empleados en viajes de vacaciones. Robert Ley es considerado por muchos como el que sienta las bases del turismo masivo de nuestros días.

Los miembros del DAF, en el que se organizaba una gran parte de los trabajadores, empleadores y funcionarios alemanes, eran al mismo tiempo miembros de KdF y pagaban una cuota mensual de al menos 0,50 marcos.

Los ingresos de DAF crecieron de 281 millones de marcos en 1933 a 538 millones en 1939. La gran mayoría fueron mensualidades. El KdF fue subsidiado por el DAF con 8 millones de marcos en 1934, 14,3 millones en 1935 y para 1938 con 32,5 millones de marcos. Las expectativas de que KdF se autofinanciara a través de los ingresos del viaje no se cumplieron.

Hans Frank, Consejero Jurídico y Gobernador de Polonia diría en una oportunidad:

Cada trabajador tenía acceso al disfrute de unas actividades artísticas, sociales y deportivas, mediante la aportación de unas cantidades verdaderamente irrisorias

Para 1939 el número de afiliados al $\mathrm{KdF}$ era alrededor de 25 millones de personas, considerando que la población alemana de la época era de 79 millones (incluyendo Austria y Bohemia-Moravia). Todos los trabajadores alemanes tenían la obligación de afiliarse y abonar sus cuotas. La organización colapsó a fines de 1939 y varios proyectos como el complejo de vacaciones de Prora, nunca fueron terminados.

Prora fue diseñado como un colosal complejo de vacaciones por los nazis en la isla Rügen. El enorme complejo de edificios mide 4,5 kilómetros de largo y fue construido entre 1936 y 1939 como un proyecto del KdF. Aunque los ocho edificios idénticos se planificaron como un lugar de vacaciones, nunca se usaron para este propósito. El complejo es un ejemplo particularmente sorprendente de la arquitectura del Tercer Reich.

Robert Ley imaginó Prora como un paralelo a los Butlins: (campamentos de vacaciones) británicos diseñados para proporcionar vacaciones asequibles para el trabajador promedio. Prora fue diseñado para albergar a 20,000 turistas, bajo el ideal de que cada trabajador merecía 
unas vacaciones en la playa. Diseñado por arquitecto Clemens Klotz, que ganó un concurso de diseño supervisado por el arquitecto en jefe de Adolf Hitler, Albert Speer, todas las habitaciones fueron planeadas con vista al mar, mientras que los corredores y el saneamiento se encuentran en el lado de da a tierra. Cada habitación medía 5 metros por 2,5 metros; debía tener dos camas, un armario y un lavabo. Había baños comunes con duchas en cada piso.

Los planes de Hitler para Prora eran mucho más ambiciosos. Quería un gigantesco centro turístico marítimo con 20,000 camas:

\section{"el más poderoso y grande que jamás haya existido"}

En el medio de Prora, un enorme edificio debía ser construido. Al mismo tiempo, Hitler quería que se convirtiera en un hospital militar en caso de guerra. Hitler insistió en que se incluyan los planos de un gigantesco salón central cubierto y que fue diseñado por el arquitecto Erich Putlitz y tenía la intención de poder acomodar a los 20,000 invitados al mismo tiempo. Los planes incluían dos piscinas de olas, un cine y un teatro. También se planificó un gran muelle para buques de pasajeros. Los diseños de Prora ganaron un premio Grand Prix en la Exposición Mundial de París de 1937.

La construcción comenzó en 1936 y durante los pocos años que Prora estuvo en construcción, todas las principales empresas de construcción del Reich y casi 9,000 trabajadores participaron en este proyecto. Con el inicio de la Segunda Guerra Mundial en 1939, la construcción de Prora se detuvo y los trabajadores de la construcción se trasladaron a la planta de armas $\mathrm{V}$ en Peenemünde. Los ocho bloques de viviendas y el teatro y el cine quedaron como cascarones vacíos. Las piscinas y la sala de fiestas nunca se terminaron. Durante la campaña de bombardeos aliados, muchas personas de Hamburgo se refugiaron en uno de los bloques de viviendas, y más tarde se alojaron refugiados del este de Alemania. Al final de la guerra, estos edificios albergaban personal auxiliar femenino de la Luftwaffe.

Otro hecho interesante que nos indica la importancia del Turismo en la Alemania nazi es la creación de la Haus des Fremdenverkehrs (Casa del Turismo) en el distrito de Tiergarten en Berlín, era un edificio que no se terminó, pero que era parte de la nueva capital mundial de Alemania. Fue una gran estructura con 120 metros, que iniciaba en la Runden Platz. El proyecto de la Casa del Turismo fue obra del arquitecto Theodor 
Dierkmeier, que en 1936 ganó el primer premio para su construcción, colaborando con él también el arquitecto Hugo Röttcher. El 14 de junio de 1938 el ministro de propaganda alemán, Joseph Goebbels; Albert Speer, inspector general de la capital y Hermann Esser colocaron la primera piedra para su construcción en presencia del Führer Adolf Hitler.

La Casa del Turismo fue el edificio menos dañado por los bombardeos aliados durante la guerra. Después de 1945, el edificio, sin terminar, se mantuvo durante varios años, siendo utilizado como parque infantil y piscina al aire libre hasta finales de la década del cincuenta, finalmente fue demolido en 1962.

En 1937 el KdF tenía 4,400 empleados y aproximadamente 106,000 voluntarios; en 1939 esta cifra había aumentado a 7,000 y 135,000 respectivamente. Para esta época el KdF había vendido más de 45 millones de paquetes turísticos y excursiones organizadas. El KdF contaba con supervisores en cada fábrica y taller con más de 20 trabajadores. La organización llegó a estar presente en los 32 Reichsgau, 771 provincias y 15,051 grupos locales.

Los nazis también intentaron atraer el Turismo receptivo. Esta tarea fue responsabilidad de Hermann Esser, secretario del Ministerio del Reich para la Ilustración Pública y Propaganda (Ministerium für Volksaufklärung und Propaganda). Se editó una serie de folletos a todo color y en varios idiomas titulados Deutschland (Alemania), que mostraba a Alemania como una nación pacífica e idílica, incluso llegando a mostrar fotos sonrientes de Joseph Goebbels en plena celebración del carnaval de Colonia, aunque la veracidad de esas imágenes sean discutidas aún hoy en día.

Uno de los programas más ambiciosos del KdF para los trabajadores alemanes fue poner en marcha la fabricación de un automóvil a un precio popular, el KdF-Wagen, que posteriormente se haría famoso mundialmente con el nombre de escarabajo Volkswagen (auto del pueblo). Este fue originalmente un proyecto emprendido a petición personal de Adolf Hitler al fabricante y diseñador de automóviles Ferdinand Porsche. Cuando la industria automovilística alemana no pudo satisfacer la demanda de Hitler de vender el Volkswagen aproximadamente en 1000 marcos, el proyecto fue adquirido por el Frente Alemán del Trabajo. Ahora trabajando para el DAF, Porsche construyó la nueva fábrica del Volkswagen en Fallersleben a un costo enorme, el que fue parcialmente cubierto por los fondos acumulados y la transferencia de las cuotas pagadas por los trabajadores miembros del DAF. 
El Volkswagen se vendería a los trabajadores alemanes en un plan de cuotas, los compradores del automóvil efectuaron pagos, colocándose sellos en un cuaderno de ahorro, que cuando estuviera lleno, se canjearía por el automóvil. Debido a la guerra y al cambio de producción, ningún ciudadano recibió un KdF-Wagen (aunque después de la guerra, Volkswagen dio a algunos clientes un descuento de 200 marcos por tener aún sus cuadernos con sellos). Todo el proyecto era financieramente poco solvente, y sólo la subvención del régimen nazi lo hizo posible. La fábrica del KdF-Wagen se transformó para producir el Kübelwagen (el equivalente alemán del jeep) durante la guerra. Los pocos vehículos que se produjeron fueron asignados al cuerpo diplomático, oficiales y jerarcas nazis.

El KdF no estuvo exento de recibir reconocimientos; tal es así que recibió en 1939 la Copa Olímpica, galardón otorgado por el Comité Olímpico Internacional durante la presidencia del belga conde Henri de Baillet-Latour.

Las actividades del KdF quedaron en la práctica suspendidas desde fines de 1939 debido a las urgencias financieras causadas por el inicio de la Segunda Guerra Mundial.

\section{REFERENCIAS BIBLIOGRÁFICAS}

AGUIRRE, J. F. (1980). La segunda guerra mundial. España. Editorial Argos Vergara.

ARGYLE, Chr. (1983). Cronología De La Segunda Guerra Mundial. Colombia. Educar Cultura Recreativa.

CASTILlO YUI, N. C. (1987). Turismo, fundamento y desarrollo. Perú. Editorial Art Lautrec S.R. Ltda.

COOPER, Chr.; FLETCHER, J.; FYALL, A.; GILBERT, D. y WANHILL, S. (2007). El turismo teoría y práctica. España. Editorial SINTESIS.

FERNÁNDEZ FUSTER, L. (1973). Teoría y técnica del turismo. España. Editora Nacional. 
JACKSON, R. (2002). Submarinos del mundo. España. Editorial LIBSA.

KATCHIKIAN, M. (2000). Historia del turismo. Perú. Universidad de San Martín de Porres, Escuela Profesional de Turismo y Hotelería.

MESSENGER, Ch. (1987). La segunda guerra mundial. Colombia. Editorial NORMA.

PDA. (2009). La segunda guerra mundial. Perú. Editora El Comercio.

PRESTON, A. (1998). Jane's fighting ships of world war II. Estados Unidos. Crescent Books.

TIME LIFE FOLIO. (1995). La segunda guerra mundial. España. Ediciones Folio. 
